\title{
Development Trend of NC Machining Accuracy Control Technology for Aeronautical Structural Parts
}

\author{
Qingchun Xiong, Qinghua Zhou \\ School of Aeronautics and Astronautics, Sichuan University, Chengdu, China \\ Email: xiongqingchun@163.com
}

How to cite this paper: Xiong, Q.C. and Zhou, Q.H. (2020) Development Trend of NC Machining Accuracy Control Technology for Aeronautical Structural Parts. World Journal of Engineering and Technology, 8, 266-279.

https://doi.org/10.4236/wjet.2020.83022

Received: April 26, 2020

Accepted: July 14, 2020

Published: July 17, 2020

Copyright ( 2020 by author(s) and Scientific Research Publishing Inc. This work is licensed under the Creative Commons Attribution International License (CC BY 4.0).

http://creativecommons.org/licenses/by/4.0/

(c) (i) Open Access

\begin{abstract}
High-performance five-axis computer numerical control machine tools are widely used in the processing of Aeronautical Structural parts. With the increase of service life, the precision of CNC machine tools equipped by aeronautical manufacturing enterprises is declining day by day, while the new generation of aircraft structural parts are developing towards integration, large-scale, complexity, thin-walled and lightweight. It is very easy to produce dimension overshoot and surface quality defects due to unstable processing technology. The machining accuracy of aircraft structural parts is also affected by complex factors such as cutting load, cutting stability, tool error, workpiece deformation, fixture deformation, etc. Because of the complexity of structure and characteristics of Aeronautical Structural parts, the consistency and stability of cutting process are poor. It is easy to cause machining accuracy problems due to tool wear, breakage and cutting chatter. Relevant scholars have carried out a lot of basic research on NC machining accuracy control and achieved fruitful results, but the research on NC machining accuracy control of Aeronautical structural parts is still less. This paper elaborates from three aspects: error modeling method of NC machine tools, error compensation method, prediction and control of machining accuracy, and combines the characteristics of Aeronautical Structural parts, the development trend and demand of NC machining accuracy control technology are put forward.
\end{abstract}

\section{Keywords}

Aeronautical Structural Parts, Machining Accuracy, Error Compensation, Machining Accuracy Control 


\section{Introduction}

In order to meet the performance requirements of a new generation of aircraft with long life and lightweight structure, new technologies, new structures and new materials have been widely used. In aircraft design, in order to improve the strength and reliability of aircraft, the load-bearing components mainly use integral components, and the thin-walled integral frame structure is the main structure, which makes the material removal amount of the cutting process large, removal rate as high as $90 \%$. Compared with previous assembly modes of welding and riveting for aircraft structural parts, large integral structural parts reduce the number of parts and assembly and welding procedures, improve the structural strength and reliability, and effectively reduce the weight of the whole aircraft, so as to significantly improve the performance of the aircraft. The rapid development of aircraft structural parts not only improves the performance of aircraft, but also brings severe challenges to manufacturing technology.

Machining accuracy is an important index to evaluate whether parts are qualified or not, and it is also the primary index to reflect the technical level of NC machining. It is of great significance for enterprises to improve efficiency and reduce cost by analyzing factors affecting errors in NC machining, predicting and compensating errors, and improving machining accuracy. There are many factors affecting the machining accuracy of CNC machine tools [1] [2], such as machine tool manufacturing error, thermal deformation error, vibration error, control system error, etc. According to the different structure and control system of NC machine tools, the positioning accuracy of multi-axis NC machine tools is determined by different error sources. In a specific CNC machine tool, there are many error sources, including geometry, static and dynamic load, thermal error, servo system parameter mismatch, etc. These error sources affect the positioning accuracy of tool tip in a complex way, and ultimately affect the processing accuracy of parts.

There are two kinds of methods to guarantee the accuracy of NC machining [3]: error prevention method and error compensation method. The former improves the overall accuracy of machine by improving the manufacturing accuracy and stiffness of machine parts and adjusting the assembly accuracy. The latter mainly compensates the regular errors such as original manufacturing error and thermal deformation error by adding compensation program in the control system, which is easy to implement and low cost. In order to improve the market competitiveness of their products, machine tool manufacturers attach great importance to error prevention and error compensation methods, and have developed some mature products for users to choose. In the practical application of machine tool end users, error prevention method mostly focuses on hardware adjustment of mechanical structure, such as clearance adjustment of kinematic pairs, bearing pre-tightening, etc. Error compensation method focuses on software adjustment of control system, such as reducing the original manufacturing error through kinematics calibration. Typical kinematics calibration of serial machine tools includes 12-line method and 14-line method, while kine- 
matics of parallel machine tools. The calibration method includes vector closed-loop differential method and so on. The thermal deformation error can be reduced by adding thermal compensation module in the control system.

Scholars have carried out a lot of research on NC machining accuracy control. In the following chapters, error modeling, error compensation, machining accuracy prediction and control are described.

\section{Error Modeling of NC Machine Tools}

The sources of machining errors are complex. Finnish scholar Rahman et al. [4] proposed that the corresponding relationship between errors of NC machine tools and errors of machined parts can not be established accurately. However, in order to obtain higher processing accuracy, it is feasible to analyze the main error sources of machine tools in specific environments, to model and compensate errors to improve processing accuracy. The research shows that the geometric and thermal errors of CNC machine tools account for $45 \%-65 \%$ of the error sources, and they are the main error sources (Table 1).

The error modeling methods of NC machine tools mainly include multi-body system theory [5], artificial neural network [6], grey theory [7], least square fitting [8], time series analysis [9]. Error modeling is the technical basis of machining accuracy prediction and error compensation.

\subsection{Geometric Error Modeling of NC Machine Tools}

The geometric error modeling of NC machine tools is to establish the relationship model between the geometric motion errors of machine tools and the position and posture errors of machine tools.

In 1986, Han et al. [10] used Fourier transform to establish error model, and used computer control to improve the positioning accuracy of machine tool rotary table. In 1988, Reshetov et al. [11] used variational method to analyze the accuracy of NC machine tools, deduced the mathematical model of small displacement, geometric error and forming system of NC machine tools, and summarized the generalized precision model of arbitrary structure under the condition of small angle error.

Table 1. Proportion of major error sources of CNC machine tools.

\begin{tabular}{|c|c|c|c|}
\hline \multirow{2}{*}{ Machine Tool Error } & Geometric error & $20 \%-30 \%$ & \multirow{2}{*}{$45 \%-65 \%$} \\
\hline & Thermal error & $25 \%-35 \%$ & \\
\hline \multirow{4}{*}{$\begin{array}{l}\text { Machining } \\
\text { process error }\end{array}$} & Tool Error & $10 \%-15 \%$ & \multirow{4}{*}{$25 \%-40 \%$} \\
\hline & Fixture error & $6 \%-10 \%$ & \\
\hline & $\begin{array}{l}\text { Working thermal error and } \\
\text { elastic deformation error }\end{array}$ & $3 \%-5 \%$ & \\
\hline & Operational error & $6 \%-10 \%$ & \\
\hline \multirow{2}{*}{ Detection error } & Installation error & $2 \%-5 \%$ & \multirow{2}{*}{$10 \%-15 \%$} \\
\hline & Uncertainty error & $8 \%-10 \%$ & \\
\hline
\end{tabular}


In 1991, Liu et al. [12] put forward the theory of multi-body system dynamics method, and expounded the calculation methods of low-order body array, matrix transformation, partial velocity and partial angular velocity. In 1993, Kiridena et al. [13] described the coordinate transformation between adjacent moving parts by means of D-H (Denavit-Hartenberg) mechanism method. In 2003, Lin et al. [14] proposed a method of geometric error modeling for five-axis linkage machine tool, matrix summation method, which decomposes kinematics equation into six components, each component has clear physical meaning, greatly reduces calculation, and makes kinematics model easy to manage and understand. In 2003, Lei et al. [15] used the fourth-order homogeneous matrix to establish the transformation relationship among the motion coordinates of CNC machine tools. The above research shows that in the past 20 years, multi-body system theory and homogeneous transformation have been widely used in geometric error modeling of machine tools.

Some scholars have studied the spatial geometric accuracy of machine tools, devoted themselves to finding the corresponding relationship between the spatial error of machine tools and the processing accuracy of parts, and carried out sensitivity analysis of the relevant error sources. In 2012, Ibaraki et al. [16] pointed out that the spatial accuracy of machine tools is represented by mapping of tool position and direction vector errors. In the latest commercial machine tool CNC, the numerical compensation of spatial errors is achievable. In 2014, Tian et al. [17] modeled the geometric errors of machine tools and analyzed their sensitivity. An error model of RRTTT machine tools was established by using screw theory and rigid body kinematics. The compensable and Non-compensable error sources were clearly separated, which provided a reference for machine tool designers and users.

In conclusion, the geometric error modeling method based on multi-body system theory kinematics and homogeneous coordinate transformation is still widely used.

\subsection{Thermal Error Modeling of NC Machine Tools}

The thermal error modeling methods of NC machine tools mainly include finite element method, regression analysis, neural network, grey system theory, fuzzy reasoning system, etc.

In 1996, Chen et al. [18] established a thermal error model based on artificial neural network and multiple regression analysis for machine tool errors under dry cutting and pouring coolant conditions. In 1996, Yang et al. [19] used cerebellar model articulation controller neural network (CMANN) to establish the error model with the thermal error and key point temperature of the processing center as the research object. In 2000, Mize et al. [6] selected some discrete point temperatures as model inputs on CNC machine tools, and established a thermal error model by using the neural network method of fuzzy artificial resonance theory. In 2003, Lee S K et al. [20] introduced the finite element method into the thermal error modeling of NC machine tools for thermal deformation of guide- 
way or thermal error caused by temperature rise of process system environment.

In 2005, Yang et al. [21] deduced a model adaptive method on the basis of dynamic model modeling method. Combining the adaptability of recursive model based on Kalman filter parameter estimation technique and multiple sampling horizons with the intermittent probing of machining process, the cutting problem was solved. The problem of thermal error updating caused by continuous change of cutting process. In 2005, Hong et al. [22] used the integrated recurrent neural network (IRNN) method to model the thermal error of the spindle in terms of the prediction accuracy and robustness of the model. In 2010, Wang et al. [23] combined linear regression model, rough-set theory and $\mathrm{K}$-means theory, proposed a thermal error modeling method for NC machine tools. In 2010, Guo et al. [24] proposed to establish the thermal error model of CNC machine tools by using back propagation neural network based on ant colony algorithm, and used clustering method to select four key measurement points on CNC machine tools. According to experience and experiment, the release of heat source target temperature sensor was determined. The key temperature sensor readings are selected by statistical method to model the error of the target machine tool.

Most of the theoretical methods of thermal error modeling for NC machine tools are based on the actual working conditions of the machine tools. For the factors affecting thermal error, the corresponding functional mathematical relationship model is established. After experimental training, accurate error model is obtained. From the point of view of engineering practicability, the thermal error model can be more accurate and has practical guiding significance only if the accurate processing environment and the temperature distribution of each part of the machine tool are obtained.

\section{Error Compensation of NC Machine Tools}

Based on the analysis of the causes of errors and the theoretical methods of error modeling, exploring the technical methods of error compensation and applying them to engineering practice is the key to improve the machining accuracy of NC machine tools. Scholars have put forward a series of error compensation techniques for NC machine tools from the point of view of cost and popularization.

In the early stage, the manufacturer of NC machine tools put forward the error prevention method of NC machine tools. Starting from the design, manufacture, assembly and debugging of NC machine tools and their parts, the error can be reduced from the angle of hardware. The biggest characteristic of error compensation method is that it does not directly reduce the size of error source, but directly guarantees the accuracy of tool tip movement through software (control system) adjustment after the machine tool is manufactured. Error compensation method is used to compensate errors that can not be eliminated by adjusting mechanical structure, such as permanent deformation or manufac- 
turing errors of parts, and regular dynamic errors such as thermal deformation errors. The general implementation steps of the error compensation method are as follows: 1) establishing the mapping relationship between the error source and the terminal (tool tip) error according to the error source to be compensated; 2) identifying the error magnitude of the error source or obtaining the transfer function of the error source and the terminal error directly; 3) compiling the error compensation software to complete the error compensation. Error compensation method reduces terminal error by adding additional compensation value, so accurate error compensation function is the key.

\subsection{Research on Compensation Method for Modifying Compensation Parameters of CNC System}

Modifying the corresponding compensation parameters in CNC system to achieve the purpose of compensation has been realized in engineering application. SIEMENS, FANUC, HEIDENHAIN and other CNC systems have integrated error compensation function modules, which can usually compensate screw pitch error, reverse clearance error, repeated positioning error of motion axis, straightness error of guide rail or spindle, verticality error and so on.

The feed axis of NC machine tool is precisely controlled by servo motor through voltage signal. In view of this characteristic of NC machine tool, in 1990, Yee et al. [25] proposed a feedback compensation method for feed axis position loop of NC machine tool, and developed a position feedback loop error compensation system which can be integrated into the control system of threeaxis NC machine tool, and achieved good compensation effect. In 2004, Choi et al. [26] revised the corresponding compensation parameters in NC system based on the error data measured by contact probe, aiming at the compensation program in NC system of three-axis NC machine tools, and improved the cutting accuracy of machine tools. In order to compensate the dynamic errors of NC machine tools, Yang Jianguo et al. [27] proposed an external coordinate system origin offset method in 2005. The error compensation system has the function of external mechanical origin coordinate offset. The compensation value is sent into the system through the I/O interface of the NC system. In 2012, Cui et al. [28] used multi-body theory to model the spatial error of NC machine tools, and used the coordinate system origin offset function of Siemens NC system to realize error compensation. In 2012, based on the error prediction model of five-axis machine tools, SHEN et al. [29] proposed a geometric error compensation method to modify rough interpolation data for open CNC systems, and a coordinate offset geometric error compensation method combined with CNC-PLC for non-open CNC systems. The experimental results show that the offset compensation method can effectively compensate the geometric and thermal errors of machine tools. In 2013, Yang et al. [30] developed a real-time error compensation function module based on the bottom communication of CNC. The real-time temperature data and coordinate axis errors collected were sent to the real-time error compensation function module of $\mathrm{CNC}$ to improve the process- 
ing accuracy.

\subsection{Research on Compensation Method for Modifying NC Code}

With the increasing complexity of parts, the structure of NC machine tools becomes more and more complex, and G code compensation method emerges as the times require.

In 2002, Zhang et al. [31] used rigid body kinematics theory and homogeneous coordinate transformation to establish a general spatial error model for the error of the end tool relative to the workpiece, and improved the machining accuracy by modifying the error algorithm of G code. In 2003, Eskandari et al. [32] in order to explore the relationship between thermal error of NC machine tool and spindle speed and processing time, the error model was established by combining regression analysis, neural network and fuzzy logic algorithm, and the processing accuracy was improved by modifying G code. In 2010, Zhu et al. [33] proposed a software-based error compensation strategy. The geometric error components of five-axis machine tools are identified by laser interferometer and spherical rod system. The generalized error model based on multi-body system (MBS) and homogeneous transfer matrix (HTM) is used to obtain the comprehensive error. The geometric error is compensated by modifying NC code. In 2013, Zhu et al. [34] established a prediction model of workpiece positioning error caused by fixture installation error and geometric error for one-side two-pin fixture. The error parameters along 6 degrees of freedom are calculated by the model, and the NC code can be compensated by using the "Frame for-mation" function of NC system or by modifying NC code in post-processing.

Although the compensation method of modifying NC code is easy to implement and widely used, it is mostly offline modification. If online NC code modification can be realized, the real-time performance of error compensation can be improved.

\subsection{Research on Other Compensation Methods}

Over the past 15 years, scholars have continued to carry out fruitful research on the real-time improvement of focus error compensation, the prediction and compensation of comprehensive error and spatial error. In 2003, Lei et al. [15] studied the real-time error compensation method based on the geometric error model established by the fourth-order homogeneous matrix. In 2017, Wu et al. [35] proposed a comprehensive geometric error prediction and compensation method for the influence of the geometric error of translation axis on the positioning accuracy of double ball bar (DBB) in multi-axis machine tools. In 2018, Xiang et al. [36] proposed an analysis and compensation method for geometric errors of six-axis NC grinding machine for spiral bevel gears. Using the screw theory and the forward and inverse kinematics modeling, the spatial error prediction and compensation are realized.

The key of error compensation technology for NC machine tools lies in the 
effectiveness of improving the actual processing accuracy of NC machine tools in practice. The method can be used as long as the processing accuracy can be improved with the lowest cost and the most effective way to make the products meet the manufacturing requirements.

\section{Prediction and Control of NC Machining Accuracy}

Before the machine tool users face a complex cutting process of new structural parts, the complexity of the error sources in the processing process makes it difficult to determine whether the new processing process can meet the requirements of manufacturing accuracy in advance.

Traditionally, through "experience judgment" or "trial cutting method" to evaluate whether the future processing can meet the requirements of manufacturing accuracy, such as cutting NAS979 (Figure 1) and NAS979 conical table (Figure 2), the general evaluation of the performance and processing accuracy of $\mathrm{NC}$ machine tools is realized, and the development of NC processing technology is promoted. However, some surface features of complex parts are processed by the machine tool which accepts the conical table specimens. This shows that the evaluation of dynamic machining accuracy of $\mathrm{CNC}$ machine tools by the conical table specimens is not comprehensive enough. The main reason is that the characteristics of conical table specimens are relatively simple, only plane and conical surface. In recent years, scholars have done a lot of research on the development of new inspection specimens for NC machine tools, such as quadrangular cone table test specimens (Figure 3), S-shaped test specimens (Figure 4), etc. Among them, S-shaped test specimens are widely used, which can be applied on five-axis machine tools with different structures as shown in Figure 5.

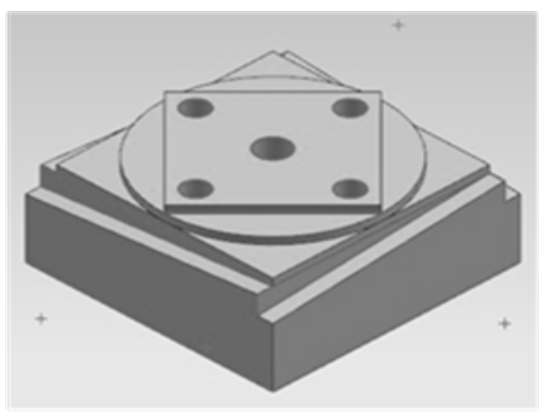

Figure 1. NAS979 specimens.

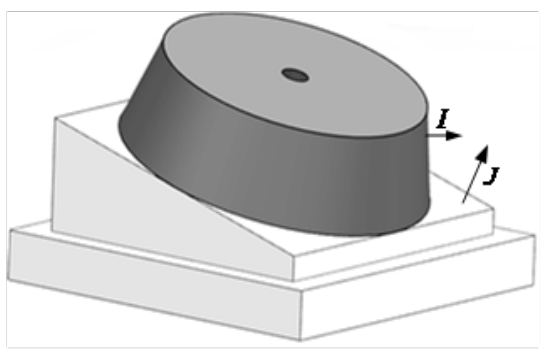

Figure 2. NAS979 conical table specimen. 


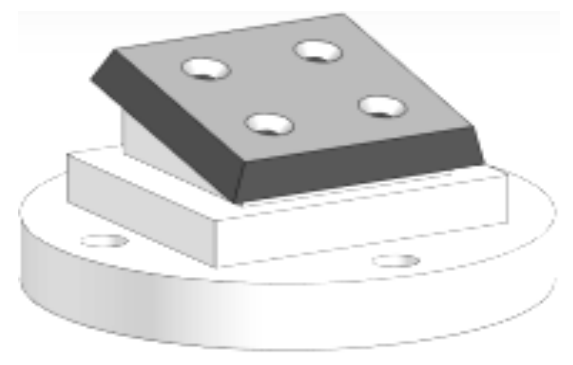

Figure 3. Quadrangular cone table specimens.

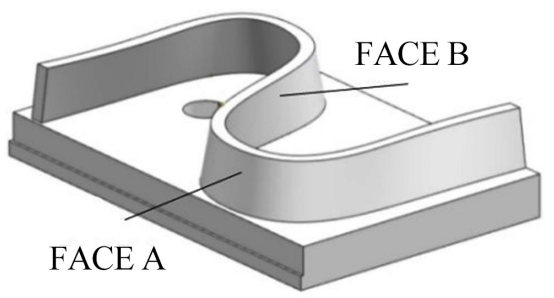

Figure 4. S-shaped specimens.

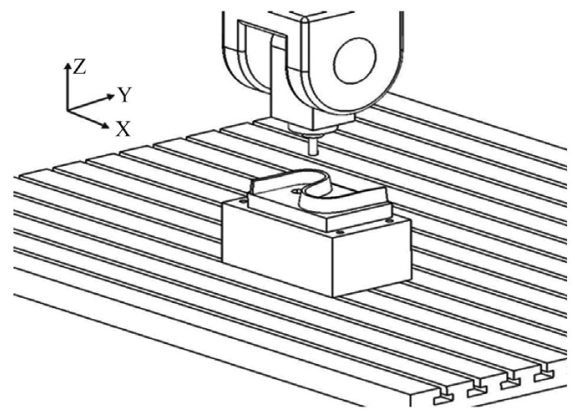

(a)

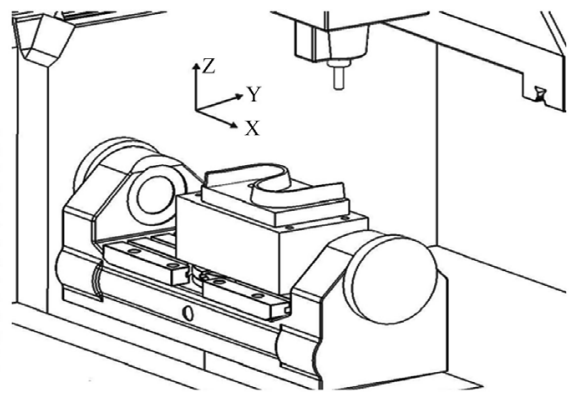

(b)

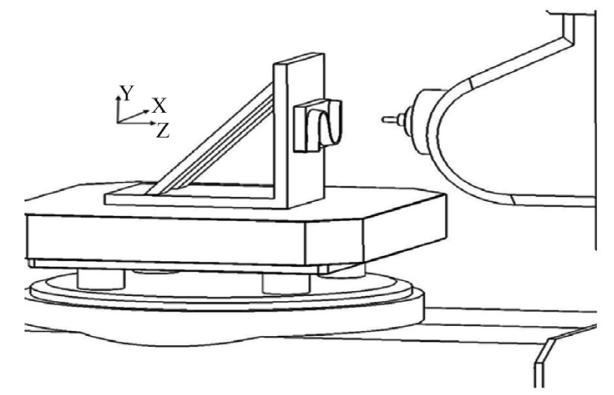

(c)

Figure 5. Application of S-shaped specimen in machine tools of different structural types. (a) Double Swing Head Machine Tool; (b) Machine Tool with Double Turntable Structure; (c) Hybrid Structure Machine Tool.

For complex high-value parts, "experience judgment" is easy to make mistakes, and "trial-cutting" is time-consuming and expensive. If the processing accuracy can be predicted, a reasonable process plan can be planned to realize the optimal allocation of manufacturing resources without trial-and-error.

Because the prediction and control of machining accuracy is of great significance, this direction has always been a research hotspot. With the breakthrough 
of geometric error modeling, thermal error modeling and simulation technology, the prediction of static error is no longer a difficult problem. In the past 10 years, more research has been carried out in combination with physical phenomena such as cutting force, friction and wear, tool deformation and so on. In 2002, Lubihong et al. [37] realized the prediction of machining accuracy on the basis of detecting and identifying the movement error and cutting force deformation error of the process system. In 2011, Dang Jianwei et al. [38] obtained processing errors from the prediction of milling force and the calculation of tool deformation. In 2012, Fan et al. [39] studied the prediction method of machine tool processing accuracy degradation. It is pointed out that after a long period of cutting, there will be obvious wear on the contact surface between the guide rail and the guide rail. With the increase of wear, the accuracy of the machine tool will be reduced. Fan proposed a mathematical model to calculate the geometric errors of sliders caused by contact deformation caused by wear, and then to predict the positioning errors. In 2013, Holub et al. [40] studied the prediction method of vertical lathe processing accuracy. The prediction method is applied to the accuracy analysis of vertical lathe under different working conditions. By simulating different working conditions, the accuracy of workspace is effectively used. The predicted results can be used to select the appropriate machine tool type and processing technology as early as possible in the bidding stage, which reduces the time required for selecting and submitting machine tool quotations. In 2014, Ding et al. [41] studied the prediction of machining accuracy of five-axis cylindrical milling based on geometric error model, and proposed a comprehensive error modeling method of process system that integrates machine tool geometric error, workpiece positioning error, tool size error and setting error to realize the prediction of machining accuracy. In 2014, Archenti et al. [42] proposed a new method to link the capability of the processing system with the accuracy of the parts. The force deviation function in the actual workspace is obtained by using special testing equipment. The spatial error is evaluated by multi-body simulation and finite element model of elastic connection, and then the deviation value of specific tool path is calculated. This method eliminates tedious processing experiments and supports the control of processing system conditions.

\section{Conclusions}

The above research work is effective from a specific point of view, and results are formed to guide production practice. But at the same time, it can not be ignored that there are some limitations in the application of some single achievements in production. For example, the prediction and compensation of NC machining accuracy are mostly based on the assumption that the machine tool is an ideal rigid body without deformation. However, the error of five-axis NC machining has time-varying characteristics, and the machining accuracy is subject to cutting load, cutting stability and tool in engineering. Due to the influence of com- 
plex factors such as errors, workpiece deformation, fixture deformation and tool deformation, the consistency and stability of cutting process are poor, which will easily cause surface quality defects due to tool wear, breakage and cutting chatter, thus resulting in irreversible surface plastic deformation, further resulting in product size overshoot, which will have a significant impact on product processing efficiency and quality. There is an urgent need to establish a set of processing accuracy control technology system based on product characteristics.

For the special machining object of complex aircraft structural parts, its structural characteristics and technological difficulties determine the complexity of its machining process, determine the difficulty of its machining accuracy control, and give birth to the development demand of its machining accuracy control technology system.

1) According to the production practice, $\mathrm{CNC}$ machine tool users should combine their own product characteristics and proceed from the production demand to form a set of effective CNC machining accuracy control technology system. Aiming at the characteristics of aircraft structural parts, such as high manufacturing accuracy, large size, easy deformation, many weak rigid structures and long processing cycle, its processing accuracy control technology system should be at least composed of three parts: processing accuracy assurance technology, processing process consistency assurance technology, surface quality prediction and simulation technology.

2) The accuracy assurance technology of aircraft structure not only needs to consider the improvement of the accuracy of the $\mathrm{CNC}$ machine tool itself, but also needs to develop the integration technology of processing and measurement in combination with the characteristics of the large size of aircraft structure, so as to solve the problems of easy deformation and difficult control of the process state. The closed-loop control of machining measurement is in line with the development trend of aircraft structure manufacturing mode from digital manufacturing to intelligent manufacturing.

3) The technology of NC machining process consistency assurance needs to be paid attention by academia and engineering field. Aircraft structural parts have long processing cycle and high manufacturing cost, and their processing accuracy control requires high consistency of manufacturing process. The influence of product structure and process characteristics on manufacturing accuracy of aircraft structural parts should be considered. For example, the influence of manufacturing resources such as NC tools on the machining accuracy and quality of products should be fully considered. The influence of NC programming trajectory and its technical standards and cutting process parameters on process consistency and processing accuracy should also be fully considered.

4) The weak rigid structure of aircraft structure determines the difficulty of surface quality control in the process of machining. In engineering practice, the manufacturing risk assessment and process risk control of large-scale parts still rely on experience, which promotes the development demand of surface quality prediction and simulation technology. Effective surface quality prediction and 
simulation technology will greatly improve the product quality control level in the production site.

\section{Acknowledgements}

The authors would like to thank the financial support from National Science \& Technology Major Project of China (2017ZX04002001).

\section{Conflicts of Interest}

The authors declare no conflicts of interest regarding the publication of this paper.

\section{References}

[1] Sartori, S. and Zhang, G.X. (1995) Geometric Error Measurement and Compensation of Machines. CIRP Annals, 44, 599-609. https://doi.org/10.1016/S0007-8506(07)60507-1

[2] Schwenke, H., Knapp, W., Haitjema, H., et al. (2008) Geometric Error Measurement and Compensation of Machines-An Update. CIRP Annals, 57, 660-675. https://doi.org/10.1016/j.cirp.2008.09.008

[3] Wu, S.M. and Ni, J. (1989) Precision Machining without Precise Machinery. CIRP Annals, 38, 533. https://doi.org/10.1016/S0007-8506(07)62762-0

[4] Rahman, M., Heikkala, J. and Lappalainen, K. (2000) Modeling, Measurement and Error Compensation of Multi-Axis Machine Tools. Part I: Theory. International Journal of Machine Tools and Manufacture, 40, 1535-1546. https://doi.org/10.1016/S0890-6955(99)00101-7

[5] Li, S.Y., Dai, Y.F., et al. (2007) Precision and Ultra-Precision Machine Tool Precision Modeling Technology. National Defense University of Science and Technology Press, Changsha.

[6] Mize, C.D. and Ziegert, J.C. (2000) Neural Network Thermal Error Compensation of a Machining Center. Precision Engineering, 24, 338-346. https://doi.org/10.1016/S0141-6359(00)00044-1

[7] Zhang, Y. and Yang, J.G. (2011) Thermal Error Modeling of Machine Tools Based on Grey Neural Network. Journal of Shanghai Jiaotong University, 45, 1581-1586.

[8] Yang, J.G., Ren, Y.Q. and Zhu, W.B. (2003) Research on Online Correction Method of Thermal Error Compensation Model for NC Machine Tools. Journal of Mechanical Engineering, 39, 81-84.

[9] Li, Y.X., Tong, H.C. and Cao, H.T. (2006) Modeling and Application of Time Series Analysis Method for Thermal Error of CNC Machine Tools. Journal of Sichuan University (Engineering Science Edition), 38, 74-78.

[10] Han, Z.J. and Zhou, K. (1986) Improvement of Positioning Accuracy of Rotating Table Microcomputer Control Compensation. Precision Engineering, 4, 115-120. https://doi.org/10.1007/978-1-349-08114-1_16

[11] Reshetov, D.N. and Portman, V.T. (1988) Accuracy of Machine Tools. ASME Press, New York.

[12] Liu, Y.W. and Zhang, D.J. (1991) Multibody Dynamics and Its Application in Machine Tools. Machine Tools, No. 1, 24-26, 49.

[13] Kiriden, V. and Ferreira, P.M. (1993) Mapping the Effects of Positioning Errors on 
the Volumetric Accuracy of 5-Axis CNC Machine Tools. International Journal of Machine Tools and Manufacture, 33, 417-437. https://doi.org/10.1016/0890-6955(93)90049-Z

[14] Lin, Y. and Shen, Y. (2003) Modelling of Five-Axis Machine Tool Metrology Models Using the Matrix Summation Approach. The International Journal of Advanced Manufacturing Technology, 21, 243-248. https://doi.org/10.1007/s001700300028

[15] Lei, W.T. and Hsu, Y.Y. (2003) Accuracy Enhancement of Five-Axis CNC Machines through Real-Time Error Compensation. International Journal of Machine Tools and Manufacture, 43, 871-877. https://doi.org/10.1016/S0890-6955(03)00089-0

[16] Ibaraki, S. and Knapp, W. (2012) Indirect Measurement of Volumetric Accuracy for Three-Axis and Five-Axis Machine Tools: A Review. International Journal of Automation Technology, 6, 110-124. https://doi.org/10.20965/ijat.2012.p0110

[17] Tian, W.J., Gao, W.G., Chang, W.F., et al. (2014) Error Modeling and Sensitivity Analysis of a Five-Axis Machine Tool. Mathematical Problems in Engineering, 2014, Article ID: 745250. https://doi.org/10.1155/2014/745250

[18] Chen, J.S. (1996) A Study of Thermally Induced Machine Tool Errors in Real Cutting Conditions. International Journal of Machine Tools and Manufacture, 36, 1401-1411. https://doi.org/10.1016/0890-6955(95)00096-8

[19] Yang, S., Yuan, J. and Ni, J. (1996) The Improvement of Thermal Error Modeling and Compensation on Machine Tools by CMAC Neural Network. International Journal of Machine Tools and Manufacture, 36, 527-537. https://doi.org/10.1016/0890-6955(95)00040-2

[20] Lee, S.K., Yoo, J.H. and Yang, M.S. (2003) Effect of Thermal Deformation on Machine Tool Slide Guide Motion. Tribology International, 36, 41-47.

https://doi.org/10.1016/S0301-679X(02)00128-7

[21] Yang, H. and Ni, J. (2005) Adaptive Model Estimation of Machine-Tool Thermal Errors Based on Recursive Dynamic Modeling Strategy. International Journal of Machine Tools and Manufacture, 45, 1-11. https://doi.org/10.1016/j.ijmachtools.2004.06.023

[22] Yang, H. and Ni, J. (2005) Dynamic Neural Network Modeling for Nonlinear, Nonstationary Machine Tool Thermally Induced Error. International Journal of Machine Tools and Manufacture, 45, 455-465. https://doi.org/10.1016/j.ijmachtools.2004.09.004

[23] Wang, K.C. and Tseng, P.C. (2010) Thermal Error Modeling of a Machine Tool Using Data Mining Scheme. Journal of Advanced Mechanical Design, Systems, and Manufacturing, 4, 516-530. https://doi.org/10.1299/jamdsm.4.516

[24] Guo, Q., Yang, J. and Wu, H. (2010) Application of ACO-BPN to Thermal Error Modeling of NC Machine Tool. The International Journal of Advanced Manufacturing Technology, 50, 667-675. https://doi.org/10.1007/s00170-010-2520-y

[25] Yee, K.W. and Gavin, R.J. (1990) Implementing Fast Part Probing and Error Compensation on Machine Tools. https://doi.org/10.6028/NIST.IR.4447

[26] Choi, J.P., Min, B.K. and Lee, S.J. (2004) Reduction of Machining Errors of a Three-Axis Machine Tool by On-Machine Measurement and Error Compensation System. Journal of Materials Processing Technology, 155, 2056-2064. https://doi.org/10.1016/j.jmatprotec.2004.04.402

[27] Yang, J.G., Zhang, H.T., Tong, H.C., Cao, H.T. and Ren, Y.Q. (2005) Application of Real-Time Thermal Error Compensation for CNC Machine Tools. Journal of Shanghai Jiaotong University, 39, 1389-1392.

[28] Cui, G.W., Lu, Y., Gao, D. and Yao, Y. (2012) A Novel Error Compensation Imple- 
menting Strategy and Realizing on Siemens 840D CNC Systems. The International Journal of Advanced Manufacturing Technology, 61, 595-608. https://doi.org/10.1007/s00170-011-3747-y

[29] Shen, H., Fu, J., He, Y., et al. (2012) On-Line Asynchronous Compensation Methods for Static/Quasi-Static Error Implemented on CNC Machine Tools. International Journal of Machine Tools \& Manufacture, 60, 14-26. https://doi.org/10.1016/j.ijmachtools.2012.04.003

[30] Yang, T.Y. (2013) Real-Time Error Compensation and Application Based on Bottom Communication of CNC System. China Mechanical Engineering, 24, 2903-2908.

[31] Zhang, H., Zhou, Y.F., Tang, X.Q. and Chen, J.H. (2002) Error G Code Compensation Technology for CNC Machining Center. Journal of Huazhong University of Science and Technology, 30, 13-16.

[32] Eskandari, S., Arezoo, B. and Abdullah, A. (2013) Positional, Geometrical, and Thermal Errors Compensation by Tool Path Modification Using Three Methods of Regression, Neural Networks, and Fuzzy Logic. The International Journal of Advanced Manufacturing Technology, 65, 1635-1649. https://doi.org/10.1007/s00170-012-4285-y

[33] Zhu, S.W., Ding, G.F. and Jiang, L. (2010) Machining Accuracy Improvement of Five-Axis Machine Tools by Geometric Error Compensation. International Conference on Advanced Technology of Design and Manufacture, Beijing, 23-25 November 2010, 348-352.

[34] Zhu, S.W., Ding, G.F., Ma, S.W., et al. (2013) Workpiece Locating Error Prediction and Compensation in Fixtures. The International Journal of Advanced Manufacturing Technology, 67, 1423-1432. https://doi.org/10.1007/s00170-012-4578-1

[35] Wu, C.J., Fan, J.W., Wang, Q.H., et al. (2018) Prediction and Compensation of Geometric Error for Translational Axes in Multi-Axis Machine Tools. The International Journal of Advanced Manufacturing Technology, 95, 3413-3435. https://doi.org/10.1007/s00170-017-1385-8

[36] Xiang, S.T., Li, H.M., Deng, M., et al. (2018) Geometric Error Analysis and Compensation for Multi-Axis Spiral Bevel Gears Milling Machine. Mechanism and Machine Theory, 121, 59-74. https://doi.org/10.1016/j.mechmachtheory.2017.10.014

[37] Lu, B.H., Ge, Y.J., Wang, Q.Y., et al. (2002) Prediction of Virtual NC Turning Accuracy. Journal of Mechanical Engineering, 38, 82-85.

[38] Dang, J.W., Zhang, W.H., Wanmin, et al. (2011) New Prediction Model of Machining Error in Milling Process. Journal of Mechanical Engineering, 47, 150-155.

[39] Fan, K.C., Chen, H.M. and Kuo, T.H. (2012) Prediction of Machining Accuracy Degradation of Machine Tools. Precision Engineering, 36, 288-298. https://doi.org/10.1016/j.precisioneng.2011.11.002

[40] Holub, M., Michalicek, M. and Vetiska, J. (2014) Prediction of Machining Accuracy for Vertical Lathes. Springer International Publishing, Berlin. https://doi.org/10.1007/978-3-319-02294-9_6

[41] Ding, G.F., Zhu, S.W., Yahya, E., et al. (2014) Prediction of Machining Accuracy Based on a Geometric Error Model in Five-Axis Peripheral Milling Process. Journal of Engineering Manufacture, 228, 1226-1236.

[42] Archenti, A. (2014) Prediction of Machined Part Accuracy from Machining System Capability. CIRP Annals-Manufacturing Technology, 63, 505-508.

https://doi.org/10.1016/j.cirp.2014.03.040 